\title{
BRIDGING THE GAP BETWEEN NASA EARTH OBSERVATIONS AND DECISION MAKERS THROUGH THE NASA DEVELOP NATIONAL PROGRAM
}

\author{
C. M. Remillard ${ }^{\text {a }}$, M. Madden ${ }^{\text {a }}$, J. Favors ${ }^{\text {b }}$, L. Childs-Gleason ${ }^{\text {b }}$, K. W. Ross ${ }^{\text {b }}$, L. Rogers ${ }^{\text {b }}$, M. L. Ruiz ${ }^{\text {b }, *}$ \\ ${ }^{a}$ University of Georgia, Center for Geospatial Research, Athens, Georgia - (cremill, mmadden)@uga.edu \\ ${ }^{\mathrm{b}}$ NASA DEVELOP National Program, Hampton, Virginia - (james.e.favors, lauren.m.childs, kenton.w.ross, lindsay.m.rogers, \\ michael.1.ruiz)@nasa.gov
}

Commission VI, WG VI/6

KEY WORDS: NASA DEVELOP National Program, Applied Science, Earth Observations, Decision Making Process

\begin{abstract}
:
The NASA DEVELOP National Program bridges the gap between NASA Earth Science and society by building capacity in both participants and partner organizations that collaborate to conduct projects. These rapid feasibility projects highlight the capabilities of satellite and aerial Earth observations. Immersion of decision and policy makers in these feasibility projects increases awareness of the capabilities of Earth observations and contributes to the tools and resources available to support enhanced decision making. This paper will present the DEVELOP model, best practices, and two case studies, the Colombia Ecological Forecasting project and the Miami-Dade County Ecological Forecasting project, that showcase the successful adoption of tools and methods for decision making. Through over 90 projects each year, DEVELOP is always striving for the innovative, practical, and beneficial use of NASA Earth science data.
\end{abstract}

\section{INTRODUCTION}

\subsection{NASA Earth Science}

Earth observing satellites make it possible to monitor and measure the constantly changing Earth and provide insight into the global domains of the geosphere, hydrosphere, atmosphere and biosphere, and their interactions through processes like the water and carbon cycles (Searby \& Ross, 2016). The Earth Science Division in the Science Mission Directorate at the National Aeronautics and Space Administration (NASA) invests in Earth observing missions that deliver synoptic views of the planet's surface and makes this information freely available to improve understanding of Earth as a dynamic system (Searby \& Ross, 2016). NASA applies that understanding to benefit society through applications research and development of decision support tools. To further bridge the gap between research and operational use of remote sensing, NASA assists institutions and their workforce to use Earth science information effectively and sustainably (Searby \& Ross, 2016).

Part of the Earth Science Division, the Applied Sciences Program (ASP) works with a diverse group of partner organizations to discover innovative and practical uses of data from NASA's satellites, airborne missions, and modelling outputs. ASP supports these organizations by combining data, knowledge, and tools to develop solutions related to nine application areas: Agriculture, Climate, Disasters, Ecological Forecasting, Energy, Health and Air Quality, Oceans, Water Resources, and Weather.

Applied Sciences' Capacity Building Program (CBP) addresses the needs of current and future decision makers in the USA and developing countries to access and apply Earth science for societal benefit. The CBP provides training and webinars, collaborates on feasibility projects, and co-develops decision support tools across its three program elements: Applied
Remote Sensing Training (ARSET), DEVELOP, and SERVIR (Searby \& Ross, 2016). These three elements focus on building capacity through 1) training and workforce development, 2) collaborative projects, and 3) community concerns using different approaches for target audiences.

\subsection{NASA DEVELOP National Program}

The CBP's NASA DEVELOP National Program (DEVELOP) builds capacity of participants and partners through collaborative feasibility projects. (Searby \& Ross, 2016). Participants work as interdisciplinary teams to apply NASA Earth observations to aid in a partner organization's decisionmaking process. DEVELOP's dual-capacity building model cultivates skills and knowledge of NASA Earth observations in participants and partners alike. DEVELOP accepts participants with a variety of skills, backgrounds, and education levels that fall into five categories: currently enrolled college students, recent graduates, early career professionals, transitioning career professionals, and active and recently transitioned military service members.

A wide variety of partners is vital to the DEVELOP model. Partner organizations include state and local governments, federal agencies, regional entities, tribal governments, international organizations and governments, NGOs and private companies. DEVELOP uses an agile project lifecycle in order to be responsive to the needs of partners. Project partners receive tools and methods that can be sustainably used to enhance their decision making.

DEVELOP operates most effectively when partner needs are clear, communication is strong, and successful project hand-off occurs. Expectations related to spatial and temporal resolution, data availability, technical ability, and workflow practices need to be clear from the beginning of a partnership. A frequent and structured communication plan must be established and maintained to ensure maximum project value. The project

* Corresponding author 
handoff of a tailored tool to a partner is a critical last step to foster rapid applied benefit.

\section{BRIDGING THE GAP BETWEEN NASA EARTH OBSERVATIONS AND DECISION MAKERS}

\subsection{The DEVELOP Model}

To explore feasibility with all of the potential users of Earth observations globally, NASA devised DEVELOP as an incubator and accelerator for applying Earth science data to decision making. To achieve this, DEVELOP uses a nimble project lifecycle in order to be responsive to the needs of any potential partner that shows interest in using NASA Earth observations in their work (Childs-Gleason et al., 2015). Projects occur within a 10 -week term and may be renewed up to three terms.

The projects are conducted by a diverse team of participants composed of roughly 3-6 college level students, graduate students, recent graduates, transitioning career professionals, and active or transitioning military service members. Each team is supported by at least one science advisor who provides guidance and expertise throughout the process.

These projects provide participants the opportunity to not only engage in research, but also build communication skills. One of the keystones of the DEVELOP program is its equal emphasis on conducting research and effectively communicating it to the public.

Project partners receive the end products and the methods that created them so that the tool can be sustainably used. In 2015, DEVELOP conducted 93 projects with 157 unique partner organizations (Childs-Gleason et al., 2015). DEVELOP seeks to bridge the gap between NASA Earth science and society, building capacity in both its participants and partner organizations to prepare them to address environmental and public policy issues.

\subsection{Best Practices}

Identifying partner needs is a critical first step in the fast-paced DEVELOP project lifecycle. The expectations of both the partner organization and DEVELOP must be clear from the beginning. It is often helpful for preliminary discussions to take place during the proposal writing stage, before the project term begins. It is important for DEVELOP to clarify what Earth observations can be provided and their spatial and temporal resolution. Additionally, it is beneficial for DEVELOP to emphasize the focussed scope of its projects, while communicating that tutorials will be provided so that partners can expand upon and update the work as they see fit.

Similarly, it is important for the project partners to understand their technical abilities including experience with remote sensing and GIS software. It is also critical for the partners to help DEVELOP understand their current workflow related to decision making and how it aligns with the project.

DEVELOP engages in domestic and international projects. International projects are most successful when an in-country partner organization is engaged in the work. Many of these projects partner with an embassy to lead communication with international partners and researchers. High success rates are also tied to projects that identify a contact person from within the organization who is focused on technical operations and can provide support for the continued use of the end products (Childs-Gleason et al., 2015).

Strong communication is imperative to the success of a DEVELOP project. DEVELOP's communication plan is structured as follows: 1) Roughly five months before the project begins, contact is established with partners and project details are discussed; 2) One month before the project, pre-project partner questionnaires are sent and the initial meeting is scheduled between the project partner and the team. If the partner is providing ancillary data, this is the time for them to share that with the team's leader; 3) During the first 2 weeks of the term, an established meeting schedule is determined and expectations of project end-products are discussed in detail; 4) Over the course of the third through eighth week of the term, the progress and challenges of the project are discussed and adjustments are made if necessary; 5) During the final two weeks, the project partner is invited to a virtual or in-person project handoff event; 6) One month following the project, post project partner questionnaires are sent and follow-up meetings are scheduled.

\subsection{Case Studies}

2.3.1 Miami-Dade Ecological Forecasting: In collaboration with Miami-Dade County, Parks, Recreation and Open Spaces Department (MDC-PROS), and the Trust for Public Land, this project focused on the design and planning of the Western Greenway (Chen et al., 2014). The Western Greenway is comprised of many scenic corridors, freshwater lakes and beaches for recreational activities. It promotes conservation efforts by highlighting Environmentally Endangered Lands and educating the public about the unique ecosystem.

The main purpose of this project was to identify suitable areas of maximum opportunities to implement a greenway with a focus on biodiversity conservation within Miami. Successfully initiating a greenway requires the parties involved to have an understanding of both the natural ecology and the social obstacles presented by the city. The team constructed a NDVI map as a proxy for vegetation condition and a land cover classification map. These maps were utilized in order to apply the LUCIS model. The LUCIS model is a land use-conflict identification strategy, which was designed to predict future development scenarios based upon weighted factors. Ultimately, recommendations were developed to enhance the decision making process by identifying areas of maximum opportunity and less potential conflict areas and providing suitable areas for the Western Greenway development (Figure 1).

NASA Earth observations served as the basis for NDVI and land cover classification maps, which played a vital role in the planning of the Western greenway. Vegetative and land cover information from these products along with ancillary datasets were used in the LUCIS model to evaluate optimal areas for promoting the greenway's three goals of conservation, agritourism, and recreation. Planning tools such as this serve as an effective way for evaluating multiple factors, a process that could not otherwise be readily achieved.

Contributions of the project to the Miami-Dade Western Greenway Online Story Map also helped to bring awareness of the greenway and importance of surrounding ecosystems to the public. This outreach component provides trail users with valuable information about specific trail sites, as well as 
provides an avenue for potential supplemental funding for the greenway's construction. Education and engagement of the public is a valuable part of the Western greenway project, where both users of the greenway and the surrounding ecosystem will reap its benefits.

The framework for the LUCIS model utilized in the project was designed so that future users could apply the model based on different weights for specific objectives from future stakeholders' input. Applicability of the specific type of suitability analysis to other scenarios should serve to be a valuable tool for future researchers.

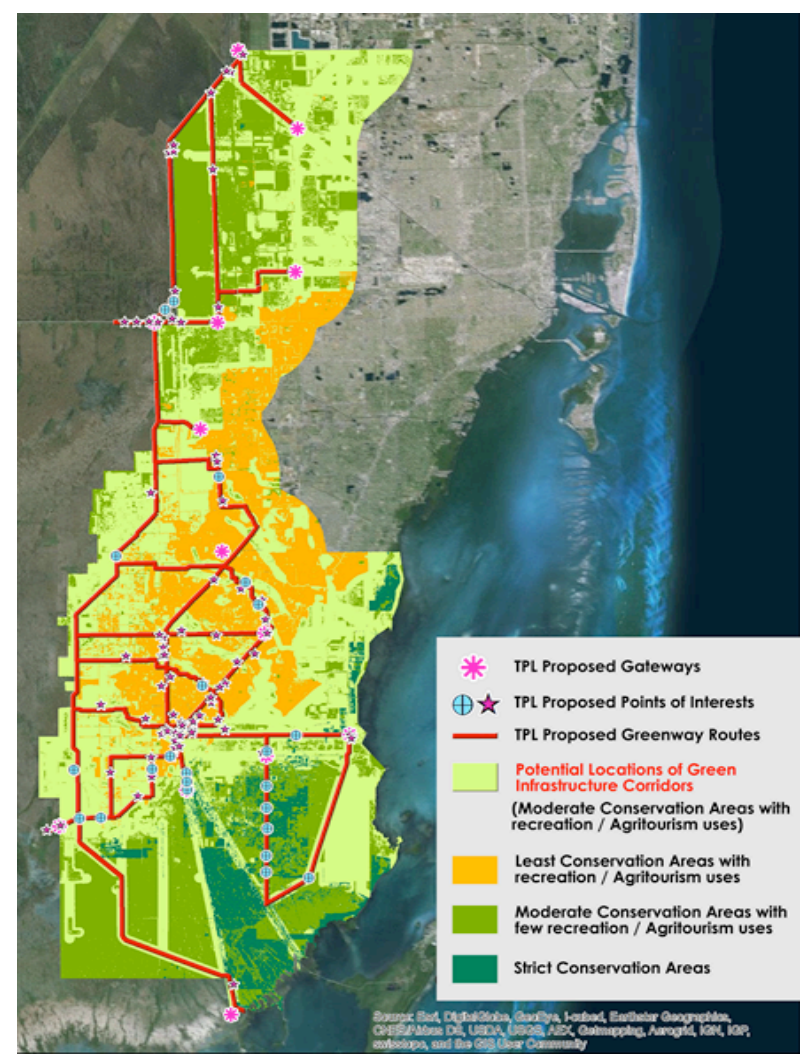

Figure 1. LUCIS model results

2.3.2 Colombia Ecological Forecasting: The goal of this project was to reinforce and support Proyecto Tití, a conservation program that works to conserve Cotton-top tamarins. They combine field research, education initiatives, and community outreach to make the conservation of natural resources economically feasible for local communities in Colombia. The integration of NASA Earth observations, technology and field data allowed the DEVELOP team to produce visual tools and quantitative information regarding historical and current conditions of Cotton-top tamarin habitat. This data can be used to forecast future conditions, identify additional suitable habitat, and provide a focus for conservation efforts.
This ecological forecasting project provided partners with broad-scale habitat information, including the identification of areas in need of protection. This information is integral to enhancing the partners' decision-making processes. The results of this project will offer them access to science-based tools in order to predict the impacts of environmental change and respond, in advance, to changes within the tamarin's range. In the past, partners have only been able to react to degradation, but ecological forecast are key to the conservation of this vulnerable species and its habitat (Remillard et al., 2015).

One of this project's strengths is its practicality and ease in repetition. Project partners welcomed the assistance of the NASA DEVELOP team in helping to provide important data on northwestern Colombia. These data will allow them to continue to select priority areas for conservation, create opportunities to connect forest patches, and examine the opportunities to purchase and reforest habitat adjacent to forested areas. The partner organization's field data was integrated with broad-scale information obtained from NASA satellites to help them achieve their goal of establishing new protected areas for Cotton-top tamarins and insure the survival of this species for future generations. Final maps and visual tools produced by the DEVELOP team were incorporated into Proyecto Tití's community outreach program, website, and educational initiatives.

The results of this work identified a variety of suitable areas within the historic range of the Cotton-top tamarin (Figure 2). By neglecting areas of least potential suitability and prioritizing the features critical to effective conservation, the NASA DEVELOP team pinpointed areas that will ultimately assist project partners in purchasing and protecting land to expand the habitat of Cotton-top tamarins. The use of NASA Earth observations, supplemented by field data, allowed for a broadscale analysis and offered the partners a new perspective on the utility of remote sensing for conservation.

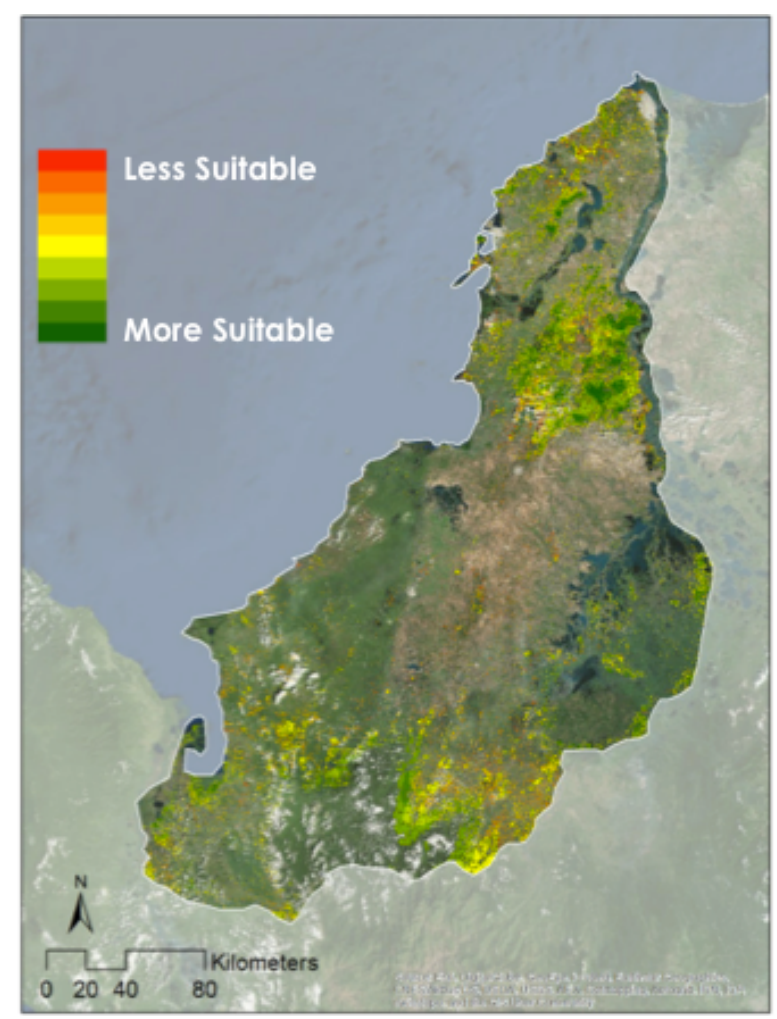

Figure 2. Suitable areas for conservation 


\section{CONCLUSION}

The NASA DEVELOP National Program fosters an immersive research environment for dual capacity building (ChildsGleason et al., 2015). Through its rapid feasibility Earth science projects, DEVELOP engages a high volume of end users and participants. Both of these groups build the skills and capabilities to use Earth observations for environmental management and policy making. DEVELOP's unique model provides a middle ground between short-term training courses and long-term research studies. This model has been successful in supporting state, federal, and international government organization to adopt methodologies and enhance decision making processes.

\section{ACKNOWLEDGEMENTS}

We would like to express gratitude to our project partners, Proyecto Tití, Fundación Proyecto Tití, Disney's Animal Kingdom, Miami-Dade County, Parks, Recreation and Open Spaces Department, and the Trust for Public Land. We would also like to thank the NASA DEVELOP National Program for their invaluable support and guidance.

\section{REFERENCES}

Chen, N., Amin, M., Anderson, L., Braun, E., Hu, T., and Zhu, L., 2014. Miami-Dade Ecological Forecasting. Unpublished manuscript, NASA DEVELOP National Program.

Childs-Gleason, L., Favors, J., Bender M., Ross, K., Rogers, L., Ruiz, M., Allsbrook, K., Crepps, G., and Miller, T., 2015. Building Capacity to Use Earth Observations in Decision Making. Poster presented at the American Geophysical Union, San Francisco, CA.

Remillard, C., Amin, M., Essig, H., Hawman, P., and Hu, T., 2015. Colombia Ecological Forecasting. Unpublished manuscript, NASA DEVELOP National Program.

Searby, N. and Ross, K., 2016. Increasing the Impacts of Capacity Building for Remote Sensing Applications. Photogrammetric Engineering \& Remote Sensing, 82(3), pp. 179-180. 